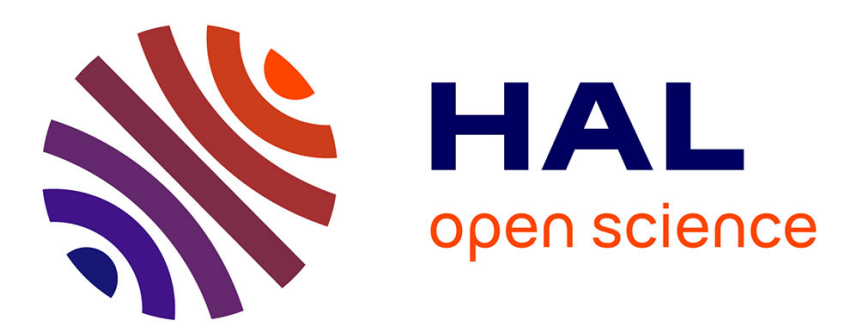

\title{
Une découverte en Amérique latine: le modèle colombien de développement et de lutte contre la violence
}

Gérard-François Dumont

\section{- To cite this version:}

Gérard-François Dumont. Une découverte en Amérique latine: le modèle colombien de développement et de lutte contre la violence. Outre-terre. Revue européenne de géopolitique, 2008, 18, pp.351-354. 10.3917/oute.018.0351 . halshs-00768637v2

\section{HAL Id: halshs-00768637 https://shs.hal.science/halshs-00768637v2}

Submitted on 22 Jul 2013

HAL is a multi-disciplinary open access archive for the deposit and dissemination of scientific research documents, whether they are published or not. The documents may come from teaching and research institutions in France or abroad, or from public or private research centers.
L'archive ouverte pluridisciplinaire HAL, est destinée au dépôt et à la diffusion de documents scientifiques de niveau recherche, publiés ou non, émanant des établissements d'enseignement et de recherche français ou étrangers, des laboratoires publics ou privés. 


\title{
UNE DÉCOUVERTE EN AMÉRIQUE LATINE : LE MODÈLE COLOMBIEN DE DÉVELOPPEMENT ET DE LUTTE CONTRE LA VIOLENCE
}

\author{
Gérard-François Dumont \\ Outre-terre I Outre-Terre
}

2007/1 - n० 18

pages 351 à 354

ISSN 1636-3671

Article disponible en ligne à l'adresse:

http://www.cairn.info/revue-outre-terre-2007-1-page-351.htm

Pour citer cet article :

Dumont Gérard-François, « Une découverte en Amérique latine : le modèle colombien de développement et de lutte contre la violence »,

Outre-Terre, 2007/1 n¹8, p. 351-354. DOI : 10.3917/oute.018.0351

Distribution électronique Cairn.info pour Outre-terre.

(c) Outre-terre. Tous droits réservés pour tous pays.

La reproduction ou représentation de cet article, notamment par photocopie, n'est autorisée que dans les limites des conditions générales d'utilisation du site ou, le cas échéant, des conditions générales de la licence souscrite par votre établissement. Toute autre reproduction ou représentation, en tout ou partie, sous quelque forme et de quelque manière que ce soit, est interdite sauf accord préalable et écrit de l'éditeur, en dehors des cas prévus par la législation en vigueur en France. II est précisé que son stockage dans une base de données est également interdit. 


\title{
Une découverte en Amérique latine : le modèle colombien de développement et de lutte contre la violence
}

\author{
Gérard-François Dumont
}

26 septembre 2007. À l'heure où j'entreprends, à l'occasion de conférences à Bogota ${ }^{1}$ et Cali $^{2}$, de parcourir ces agglomérations de Colombie, des quartiers historiques du pays à ses bidonvilles, sans oublier ses divers communes ou quartiers périurbains ${ }^{3}$ ou paraurbains ${ }^{4}$, l'Europe, et plus particulièrement la France, n'est essentiellement informée de ce pays que sous quelques aspects.

\section{Un héritage de violence}

D'une part, tant le Français que l'Européen, l'Américain ou l'étranger de passage peut voir, partout en France, de grandes photos représentant Ingrid Betancourt, enlevée par la guérilla des FARC (Forces armées révolutionnaires colombiennes) le 23 février 2002. Ces photos sont présentes par exemple aux grilles du Sénat comme sur la mairie de Chambéry, chef-lieu du département de Haute-Savoie, en passant par des sièges de région comme celui de l'Île-deFrance, rue de Babylone, dans le VII ${ }^{\mathrm{e}}$ arrondissement de Paris. D'autre part,

Gérard-François DumONT, professeur à l'université de Paris-Sorbonne, président de la revue Population \& Avenir, <www.population-demographie.org >.

1. Dont l'agglomération compte environ 8 millions d'habitants, et se trouve donc plus peuplée que la Bulgarie, le Danemark, la Slovaquie ou la Finlande.

2. Environ 2,5 millions d'habitants.

3. Les quartiers périurbains sont situés à la périphérie des villes et se trouvent en conséquence en continuité de cadre bâti avec ces villes.

4. Les territoires paraurbanisés correspondent à une urbanisation qui se situe au-delà des unités urbaines dans des territoires de morphologie rurale, où viennent habiter des personnes faisant des navettes quotidiennes vers un emploi en milieu urbain ; voir Dictionnaire de Géographie, Paris, Ellipses, 2005. 
montrant leur connaissance de la Colombie, des journalistes me demandent sur un ton pince-sans-rire de leur rapporter de la cocaïne.

Plus généralement, les médias européens, et français tout particulièrement, restent à l'affût de tout événement qui pourrait laisser penser que la libération d'Ingrid Betancourt serait prochaine. L'action de certains Français dans une opération aéroportée ayant utilisé, a priori sans autorisation, le territoire brésilien a été relatée, bien que son "succès » ait été l'égal de celle contre le Rainbow Warrior ${ }^{5}$ dans le port d'Auckland. Les démarches du président vénézuélien Chávez concernant Ingrid Betancourt sont davantage rapportées que l'évolution dictatoriale de son régime le conduisant à considérer tout opposant comme « fasciste».

La troisième information qui ponctue mon départ en Colombie vient de l'ancien mari d'Ingrid Betancourt, qui rend hommage au président Chávez, mais déclare en revanche que la Colombie serait dirigée par un président « d'extrême droite », M. Uribe, avec toutes les conséquences dommageables que cela signifierait pour les libertés. Cette information est celle des trois qui sollicite le plus mon esprit critique, à l'heure où Chávez souhaite imposer au Venezuela un bouleversement constitutionnel lui permettant notamment d'être toujours reconduit dans ses fonctions, alors que M. Uribe n'a demandé aucune réforme institutionnelle qui supprimerait la limitation à deux mandats ${ }^{6}$ dans son propre pays.

En outre, à la même époque de cet été 2007, les médias annoncent qu'une personne accuse le président Uribe d'avoir été, il y a plusieurs années, en très étroite relation avec certains narcotrafiquants. Comme aucune preuve n'est apportée à une telle affirmation et que jamais la lutte du gouvernement colombien contre les narcotrafiquants n'a été aussi intense que depuis le président Uribe, cette accusation semble conforme à la fameuse méthode : «Calomniez, calomniez, il en restera toujours quelque chose. »

Par ailleurs, la connaissance livresque de la Colombie permet de savoir que l'histoire de ce pays, indépendant depuis 1819, n'a pas été un lit de roses et qu'elle compte nombre d'épisodes tragiques marqués par d'importantes violences. Mais les années 2000 doivent-elles être classées parmi les pires de l'histoire colombienne?

5. L'action de coulage de ce bateau par les services secrets français en 1985 se sut très rapidement.

6. Le nombre de deux mandats a été décidé dans les années 2000. 


\section{Des avancées contre l'insécurité}

Ce que l'on voit en Colombie - et que de nombreuses photos peuvent attester -, ce dont on peut débattre dans ce pays libre, ce qui se dégage de discussions conduites dans toutes les catégories sociales, allant par exemple d'un recteur d'université à de jeunes analphabètes, conduit sans aucune hésitation à répondre négativement à cette question. Les années 2000 , si les progrès actuels se poursuivent jusqu'à la fin de la décennie puis au-delà, pourront être jugées non seulement comme les meilleures du pays, mais aussi comme celles qui auront marqué des avancées majeures.

Certes, les difficultés sont nombreuses. Les FARC occupent militairement une proportion non négligeable du territoire, malgré l'absence de soutien populaire. Il en résulte de nouveaux habitants pour les bidonvilles, avec ces Colombiens qui fuient la violence des FARC et cherchent refuge dans les grandes agglomérations. Des groupes de paramilitaires, qui se nourrissent de rackets ou d'enlèvements, continuent à sévir. Les narcotrafiquants dirigent un secteur économique toujours florissant. La question de la sécurité se constate aussi dans les contrastes entre des quartiers pauvres et, surtout en zone paraurbanisée, des quartiers protégés pour les classes moyennes qui ont réussi.

Mais, en réalité, le gouvernement colombien est parvenu à augmenter la superficie des territoires pacifiés. Ainsi se développe un tourisme rural dans la région de la vallée du Cauca, auparavant entièrement zone d'insécurité. Les efforts pour reconvertir des paramilitaires à la vie civile, permettant ainsi de libérer des quartiers qui étaient sous leur coupe, obtiennent des résultats, insuffisants, mais réels. Outre le déploiement d'une police protectrice, des mesures pratiques astucieuses, concernant les motos ou les très nombreux taxis, améliorent la sécurité. La lutte contre les narcotrafiquants obtient certains résultats comme l'attestent des arrestations de « gros bonnets ». Le nombre des candidats aux élections municipales de 2007, tués par les FARC ou les paramilitaires qui veulent empêcher la démocratie, est en diminution par rapport aux précédentes élections.

\section{Les libertés et l'implication de la société civile}

La liberté politique qui règne dans le pays progresse, offre aux départements (au nombre de 32), dont le gouverneur est élu, comme aux municipalités (au nombre de 1098), dont le maire est élu, l'occasion d'œuvrer pour le développement local, même si la corruption n'est pas totalement enrayée. La liberté d'association ou de fondations se constate dans l'ouverture d'écoles «privées », c'est-à-dire d'écoles pour les plus pauvres, y compris dans les quartiers les plus 
défavorisés, à l'exemple de cette école qui apprend à ses collégiens d'abord à faire du pain, pour la nourriture de la famille, avant de les alphabétiser. Elle se constate aussi dans la création de centres sociaux associatifs pour les orphelins, de centres de formation et de production pour des femmes, de centres d'appel aidant à la lutte contre la violence, de centres de formation intégrée situés dans des quartiers défavorisés débouchant directement sur des emplois ${ }^{7}$. D'autres mesures visent, contrairement à ce qui existe dans nombre de pays du Sud, à encourager l'investissement provenant de revenus perçus à l'étranger, en Espagne ou aux États-Unis principalement, par des émigrants colombiens temporaires ou durables.

Au total, le développement de la Colombie est incontestable, qu'il s'agisse de l'amélioration des logements ou du développement commercial dans des quartiers auparavant entièrement déshérités, de l'amélioration des logements avec des phénomènes d'émulation entre les anciens pauvres, des transports urbains, avec l'installation d'un réseau de bus en site propre à Bogota ou à Cali, de la modernisation des aéroports, du développement de l'offre touristique... Il faut ajouter l'existence d'universités de haut niveau ou une offre médicale dont la qualité attire des ressortissants des États-Unis pour un séjour le temps d'une opération et d'une convalescence.

La Colombie donne le sentiment d'une mobilisation de la société civile et d'une volonté d'innovation économique et sociale favorisées par les autorités politiques.

Le troisième pays d'Amérique latine par le nombre d'habitants, après le Brésil et le Mexique ${ }^{8}$, enregistre donc d'incontestables progrès, malgré les sommes budgétaires importantes qu'il est obligé de consacrer à l'armée et à la police. Il ne faudrait pas que cette réalité soit masquée par les aspects négatifs dont souffrent les Colombiens. Car ce grand pays a besoin aussi de soutien et de la reconnaissance internationale pour continuer à améliorer sa sécurité et son développement, qui sont d'ailleurs des termes liés.

7. Et ces équipements collectifs ne semblent pas faire l'objet de violence comme cela se constate périodiquement en France, notamment lors des semaines de violence de l'automne 2005. Autrement dit, l'Europe a des leçons à prendre en Colombie en matière de politique de la ville.

8. Gérard-François Dumont, Les populations du monde [2e éd.], Paris, A. Colin, 2004. 